\title{
Contribuições da técnica de "associação livre de palavras" para a compreensão da sexualidade na adolescência
}

\section{Contributions of "free association of words" technique for sexuality understanding in teenage}

Vânia Maria Oliveira Vieira*

\section{Resumo}

Este artigo discute parte de resultados da pesquisa' Sexualidade na adolescência: contribuições da teoria das representações sociais para a educação básica, com o apoio da Fundação de Amparo à Pesquisa do Estado de Minas Gerais (Fapemig), Edital 13/2012 - Pesquisa em Educação Básica. Especificamente, apresenta as contribuições da técnica de associação livre de palavras (Talp), processadas no software EVOC, para a compreensão da sexualidade na adolescência. Parte do princípio de que um dos aspectos da vida do adolescente que frequentemente tem sido apontado como motivo de preocupação, tanto da família como da escola, tem sido o desenvolvimento da sexualidade. Propõe identificar o núcleo central e o sistema periférico das representações sociais construídas por 139 alunos do $70,8^{\circ}$ e $9^{\circ}$ anos do ensino fundamental, de uma escola municipal de Uberaba, sobre sexualidade na adolescência. Toma como referencial teórico-metodológico a teoria das representações sociais de Moscovici (2003) e a subteoria do Núcleo Central de Abric (2000). As análises realizadas a partir dos resultados da Talp e do EVOC apontam que esses alunos estão construindo representações sociais ancoradas em elementos que demonstram uma compreensão limitada da sexualidade na adolescência. Em razão disso, o estudo mostra a necessidade de um trabalho de orientação sexual nessa escola.

Palavras-chave: Adolescência. Representações sociais. Sexualidade. Talp.

\section{Abstract}

This article discusses parts of results of a larger research, Sexuality in teenage: contributions of theory of social representations for basic education, with the support of Fundação de Amparo à Pesquisa do Estado de Minas Gerais (Fapemig), Notice 13/2012 - Research in Basic Education. It discusses, specially, the contributions of free association of technical words (Talp), processed in EVOC software for the understanding of sexuality in teenage. It assumes that one of the aspects of teenage life that has often been appointed out as a cause for concern, both the family either the school, has been the development of sexuality. It proposes to identify the peripheral and central core of social representations, built by 139 students from the 7th, 8th and 9th grade of elementary school, in a public school in Uberaba, about sexuality in teenage. It takes as theoretical and methodological reference the Theory of Social Representations of Moscovici (2003) and subtheory Central Core Abric (2000). The analyses from the results of Talp and EVOC show that these students are building social representations based on elements that demonstrate a limited understanding of sexuality in teenage. Because of it, the study shows the need for a work on sexual orientation in this school.

Keywords: Teenage. Social representations. Sexuality. Talp.

Recebido em 21/03/2018 - Aprovado em 05/10/2018

http://dx.doi.org/10.5335/rep.v26i1.6126

Doutora em Psicologia da Educação pela Pontifícia Universidade Católica de São Paulo. Coordenadora do Programa de Mestrado em Educação da Universidade de Uberaba e professora nos cursos de Pedagogia, Psicologia e Medicina. Atua também como psicóloga escolar na rede de ensino da Prefeitura Municipal de Uberaba. E-mail: vaniacamila@ uol.com.br 


\section{Introdução}

Cada vez mais, o desenvolvimento da sexualidade tem sido tema de discussão e debate na sociedade brasileira, por ser considerado um dos aspectos da vida do adolescente frequentemente apontado como motivo de preocupação, tanto da família como da escola.

Segundo as análises da pesquisa realizada por Arruda (1992), os adolescentes entre 13 e 19 anos, das escolas públicas de Campina Grande, Paraíba, demonstraram falta de informações corretas sobre a sexualidade na adolescência. $\mathrm{O}$ que eles sabem sobre este tema geralmente são informações oriundas de revistas consideradas pornográficas. $\mathrm{E}$ as orientações que raramente recebem das famílias pouco esclarecem, pois são permeadas por preconceitos e crendices, como "isto é pecado", "é feio".

É consenso entre vários autores que a adolescência é "[...] concebida como uma fase da vida do homem, [...] identificada como uma etapa marcada por tormentos e conturbações vinculadas à emergência da sexualidade" (BOCK, 2007, p. 64). E é no bojo dessas caraterísticas que a escola convive com seus adolescentes. Influenciando o processo de ensino e aprendizagem, a sexualidade se destaca como característica marcante nessa fase.

De acordo com os Parâmetros Curriculares Nacionais (PCNs) (BRASIL, 2001), a sexualidade influencia significativamente o desenvolvimento e a vida psíquica das pessoas. Além da função reprodutiva, relaciona-se com a busca de prazeres, $o$ que é uma necessidade fundamental do ser humano. Assim:

A sexualidade forma parte integral da personalidade de cada um. É uma necessidade básica [...] que não pode ser separado de outros aspectos da vida. [...] é a energia que se expressa na forma de sentir [...] influencia pensamentos, sentimentos, ações e interações e tanto a saúde física como a mental (BRASIL, 2001, p. 295).

E é sobre isso que se ocupa este estudo. A pesquisa compreende parte de um estudo que buscou identificar as representações sociais de 139 alunos de $7^{\circ}, 8^{\circ}$ e $9^{\circ}$ anos de uma escola pública de Uberaba, MG, sobre a sexualidade na adolescência. Especificamente, mostram-se as contribuições da técnica de associação livre de palavras (Talp), tratadas pelo software EVOC, para identificação do núcleo central e do sistema periférico das representações sociais construídas pelos alunos, com o propósito de tornar familiar como tem sido compreendido por eles o desenvolvimento da sexualidade na fase da adolescência.

O texto está organizado em quatro itens, descritos de forma a relatar o desenvolvimento da pesquisa: 1) Constructos teóricas acerca do objeto de estudo: a sexualidade na adolescência; 2) Percurso metodológico: a teoria das representações 
sociais e a subteoria do núcleo central; 3) As contribuições da técnica de associação livre de palavras e o software EVOC: diálogo com os dados; 4) Considerações finais.

\section{Constructos teóricas acerca do objeto de estudo: a sexualidade na adolescência}

O termo adolescência vem da palavra adolescere, que significa crescer, desenvolver-se (HARRIS, 1994). Só a partir do século XIX que a psicologia começou a preocupar-se com a adolescência. Nessa época, o precursor da psicologia da adolescência foi o norte-americano Granville Stanley Hall, com sua primeira publicação no ano de 1904, intitulada Adolescence. Hall foi o primeiro que se preocupou em categorizar os fenômenos que acontecem na adolescência, utilizando-se dos recursos científicos de sua época (SENNA; DESSEN, 2012).

Segundo Ferreira (1995), Hall conceitua a adolescência como algo universal, inevitável e uma fase em que ocorre o segundo nascimento. $\mathrm{O}$ autor sustenta, também, a importância da cultura interligada às diferenças individuais de cada adolescente. Pode-se dizer que essa publicação de Hall, considerada por muitos como revolucionária em sua época, foi fundamental para que, posteriormente, outros trabalhos pudessem ser realizados.

Hall postulou que o desenvolvimento humano ocorre por meio de formulações orgânicas (filogêneses e ontogêneses) e que se dá em etapas geneticamente determinadas. Sua argumentação teórica baseia-se na teoria da recapitulação proposta por Charles Darwin.

Hoje, os limites cronológicos da adolescência foram definidos, pela Organização Mundial de Saúde (OMS), entre 10 e 19 anos. O Brasil, entretanto, tem se valido do que foi definido pelo Estatuto da Criança de do Adolescente (ECA).

Lei 8.069, de 1990, que considera a criança a pessoa de até 12 anos de idade incompletos e concebe a adolescência como a faixa etária de 12 a 18 anos de idade, conforme Artigo $2^{\circ}$, e, em casos especiais, o estatuto é aplicável até os 21 anos de idade - artigo 121 e 142 (EISENSTEIN, 2005, p. 6).

Além dos meios jurídicos e determinações de leis, muitas teorias foram publicadas sobre adolescência. O modelo biomédico, de acordo com Davim et al. (2009), sustenta que a adolescência é uma fase do desenvolvimento humano que ocorre na segunda década da vida, em que acontece as transformações biológicas da puberdade relacionada à maturidade biopsicossocial.

Para Ferreira, durante a fase da adolescência, “[...] surgem a atração sexual, a socialização, atividades em grupo, o interesse profissional, a preocupação em constituir família. A criança que buscava o prazer transforma-se em adulto socializado, orientado para a realidade, cuja principal função é a reprodução" (1995, 
p. 16). Nesse sentido, pode-se dizer que a adolescência é uma fase de mudanças, o corpo desenvolve-se, as emoções afloram-se, os sentimentos são expressos dentro do limite máximo, e, em meio a suas peculiaridades, a sexualidade tem se destacado como ponto crucial.

A velocidade em que ocorrem mudanças em nosso dia a dia se torna cada vez maior. Não é raro o reconhecimento de que as crianças têm deixado a infância cada vez mais cedo, adolescentes tornam-se adultos fisiologicamente mais rápido e os adultos buscam uma vida mais longa e saudável.

Aberastury et al. (1983) enuncia que, na adolescência, ocorre a finalização do processo de desprendimento humano. Esse processo atravessa três momentos fundamentais da vida. O primeiro é o nascimento; o segundo surge ao final do primeiro ano, com a eclosão da genitalidade, a dentição, a linguagem, a posição de pé e marcha; e o terceiro momento aparece na adolescência, que é um período de contradições, ambivalente e doloroso, caracterizado por rupturas familiares e do ambiente circundante. Junto a todos esses aspectos, a maturidade genital levará o adolescente a identificar-se com o outro na sua busca de amor a objetos externos, $o$ que se concretizará com a descoberta do par, exigindo do adolescente o desprendimento interno dos pais.

Para a psicanálise, a adolescência marcaria um tempo de revivescência e ressignificação edípica. Ferreira (1995) diz que a adolescência faz ressurgir todos os impulsos sexuais adormecidos na fase de latência ( 6 aos 11 anos), que agora ganham novas oportunidades de satisfação, pelas modificações bioquímicas e glandulares, podendo ela ser lugar de pura repetição ou lugar de elaboração e abertura, permitindo rearranjos dos traços de memória com uma visão mais fluida do passado.

Para Erik Erikson (1987), todas as idades possuem um conflito básico, cuja solução ou permanência depende da conquista da etapa seguinte, sendo que cada etapa possui uma qualidade positiva ou negativa, e depende do indivíduo a incorporação dessas qualidades na sua personalidade, que o levarão a um desenvolvimento benéfico ou a insucessos em sua vida. Dentro da sua teoria, a adolescência faz parte da quinta fase normativa, definida em torno do conflito entre identidade e difusão de papéis. Existe no adolescente uma necessidade de integração do passado, com tudo aquilo que viveu, e o que espera do futuro, por meio dos processos de recapitulação e antecipação, o que culminará no estabelecimento da identidade na adolescência. Entretanto, se isso não ocorrer, existe o perigo de difundir-se em inúmeros papéis e prejudicará, posteriormente, o desenvolvimento do ego.

Sendo assim, a adolescência, em seu processo de desconstrução e construção, culmina na crise de identidade, pois, nessa fase, o adolescente tomará consciência do que pensa sobre ele e o seu corpo, sobre o que as pessoas pensam dele mesmo e o que ele pensa que os outros pensam sobre ele. 
Outra característica da adolescência é o convívio grupal - uma maneira pela qual os adolescentes apropriam-se de um mundo que até então não despertava interesse, tornando-se algo de grande importância. "O grupo e a identidade grupal são decisivos para a formação do jovem, como modelos de liderança. Através do grupo, o adolescente pode encontrar sua identidade" (FERREIRA, 1995, 31), sendo também essa uma construção da cultura jovem, uma característica da sociedade a partir dos séculos XIX e XX.

A convivência prolongada em grupos de pares dentro da escola e em situações sociais paralelas como clubes, esportes e festas, propiciaram o desenvolvimento de uma subcultura adolescente, caracterizado por roupas, linguagem, modismo, atitudes e comportamentos específicos que a distinguia do mundo adulto. Com a oposição ao mundo adulto, a irreverência, o desafio e a rebeldia, vieram a ser algumas das características mais marcantes desses jovens (DAVIM et al., 2009 p. 37).

Uma perda própria do início da puberdade é a da imagem do pai, da mãe ou daqueles que se responsabilizam pelo adolescente. Nesse momento, ele já não se vê propriamente em seus responsáveis, distanciando-se, nesse processo que liga ao "não eu", num distanciar-se necessário para esse novo desdobramento da sexualidade. Sobre isso, Gallatin (1978) esclarece que, por essa razão, o adolescente sente-se atormentado, principalmente por sentir culpa com relação aos desejos proibidos no emergir da puberdade.

\section{Puberdade}

Conforme Hurlock (1979), a palavra "puberdade" vem do latim pubertas, que significa "idade viril", época em que os órgãos de reprodução amadurecem e começam a funcionar. Ela subdivide-se em três estágios: pré-puberdade, puberdade e pós-puberdade.

Na pré-puberdade, o desenvolvimento físico se acelera e busca-se uma maior proximidade com o adulto. Na puberdade, há a maturidade dos órgãos genitais. Já na pós-puberdade, o adolescente demonstra a responsabilidade das cobranças do meio social, como a escolha profissional, por exemplo.

Segundo Eisenstein (2005), a puberdade é o fenômeno morfológico e fisiológico que é parte de um processo que se inicia na vida fetal e termina no completo crescimento ósseo, com o desenvolvimento das características sexuais secundárias, com a maturação da mulher e do homem em sua capacidade de fecundação, para que haja a conservação da vida humana.

Não há uma idade universal para que ocorra a progressão do desenvolvimento puberal. Nas meninas, esse processo ocorre mais cedo, por volta dos 10 anos de 
idade, já para os meninos, aos 12 anos, podendo haver uma diferença quanto à variação no ritmo dessas mudanças corporais.

É correto afirmar que essas mudanças ocorrem ao longo dos anos da adolescência. $\mathrm{O}$ adolescente começa seu desenvolvimento com o popularmente conhecido "estirão" de crescimento, sendo esta a primeira das principais mudanças físicas que ocorrem na puberdade. Ocorrendo em idades diferentes e em ambos os sexos, levará à culminação da possibilidade de reprodução.

O desenvolvimento das características sexuais secundárias dá a meninas e meninos traços físicos de "feminilidade" e "masculinidade", e essas características estão diretamente relacionadas à atração sobre o outro, não exclusivamente na questão da reprodução, mas estão ligadas às possibilidades de relacionamentos estreitados pelo sentimento.

Pode-se falar também do sentimento do adolescente sobre a perda do seu corpo infantil, ao mesmo tempo em que encontra dificuldade para se adaptar a muitas das transformações que ocorrem nessa fase.

Uma das mais difíceis tarefas de desenvolvimento para o jovem adolescente é a aceitação de seu corpo e físico modificados. Ele precisa não apenas ajustar-se às alterações normais que acompanham a puberdade, mas também precisa aceitar seus novos tamanhos, e forma como o físico que terá para o resto da vida. Mais cedo ou mais tarde, a maioria dos adolescentes faz isso (HURLOCK, 1979, p. 47).

Outro ponto importante é a insatisfação com a própria aparência física, mais comumente ligada a meninas, fato que também tem se modificado no segmento masculino, com a tendência da metrossexualidade. ${ }^{2}$ Todavia, podem ser elencados sentimentos como ansiedade e insegurança com relação à imagem corporal.

Para Hurlock (1979), os ideais sobre o corpo idealizado na infância para a vida adulta são também os enraizados pelos meios de comunicação, como também por família, amigos e atitudes gerais da cultura. Quando o púbere vê seu corpo real e compara-o com o idealizado, sob o seu entender, tem razões para preocupar-se. Mas o que está por trás dessa preocupação, senão o fato de apresentar-se adequadamente ao sexo oposto? E isso acontece pelos atributos físicos.

A imagem do corpo perfeito faz com que muitos indivíduos não aceitem o próprio corpo, gerando insatisfação com sua aparência física. Tal fato pode ser comprovado pelos altos índices de adolescentes de ambos os sexos com problemas de anorexia e bulimia, como também aqueles que aderem precocemente a academias e operações estéticas, em busca do corpo que desejam ter.

Outro elemento importante destacado por Gallatin (1978) é a necessidade de segurança e como, em nossa sociedade, apesar das modificações ocorridas, a sexualidade é ainda tratada como algo distanciado e que deve ser excluído das discussões 
nos contextos familiar e social, ficando relegada apenas aos currículos escolares, $o$ que muitas vezes não ocorre.

Ainda hoje, é comum observar a dificuldade com que diversos temas relacionados à sexualidade são discutidos. Falar e discutir sobre temas como relação sexual, DST, masturbação, virgindade, maturação dos órgãos reprodutores ainda é considerado proibido por muitas famílias. Essas discussões ainda não são vistas como uma possibilidade de aprendizado, mas apenas vinculadas a cenas de TV ou a algo que é atravessado no dia a dia da família.

Isso favorece a construção de mitos, visões distorcidas e pensamentos rígidos, que culminam em uma sexualidade mal resolvida, consequentemente, a relação com o sexo oposto será ainda mais difícil, podendo o sujeito iniciar a fase adulta sem uma preparação saudável para o convívio tanto social quanto sexual em suas relações.

Como é possível observar, à luz dos autores estudados, a adolescência não é uma fase fácil de passar. A não informação adequada da sexualidade e mesmo a ausência de uma orientação sexual, no desenvolvimento dos adolescentes, podem influenciar as representações sociais construídas por eles sobre o seu desenvolvimento. E essas representações, como afirma Moscovici (2003), influenciam os pensamentos, as ações e o modo de ser das pessoas. Na escola, o indivíduo interessa-se, principalmente, pela disposição e pelo desejo para aprender.

\section{Percurso metodológico: a teoria das representações sociais e a subteoria do núcleo central}

Esta pesquisa caracteriza-se como quantitativa-qualitativa e descritiva, tomando como referencial teórico-metodológico a teoria das representações sociais, de Moscovici (2003) e seus seguidores, bem como a subteoria do núcleo central, de Abric (2000). O locus da pesquisa foi uma escola pública de educação básica de Uberaba, MG. Os participantes foram 139 alunos adolescentes de $7^{\circ}, 8^{\circ}$ e $9^{\circ}$ anos dessa escola. Para a coleta dos dados, foi utilizada a técnica de associação livre de palavras (Talp), com processamento, em seguida, no software EVOC.

\section{A teoria das representações sociais}

A psicologia social teve início nos Estados Unidos da América, dividindo espaço com a teoria behaviorista. Segundo Santos: "A psicologia social naquele momento tira o foco do comportamento e traz para a discussão os processos mentais 
subjacentes" (2005, p. 15). Aos poucos, o indivíduo foi tornando-se objeto de atenção para o conhecimento científico e foram surgindo muitos estudos sobre a percepção social e a investigação sobre as informações que o indivíduo tem sobre o outro, e como esse outro interfere em sua dimensão psicológica.

Passou-se a estudar, na psicologia social, o conceito de representação social com o francês Serge Moscovici, em 1961, pela publicação de sua obra La psychanalyse, son imagem et son public. Para Moscovici, o que pode ser estudado dentro do campo científico muito se aproxima dos indivíduos e do conhecimento popular.

Dessa maneira, segundo Shimizu e Menin (2004), as construções que são feitas de um imaginário individual pertencem também ao coletivo. As representações sociais estão ligadas a bases sociais, psicológicas, culturais e ideológicas, relacionadas com a sociedade e seus grupos. Assim, é possível a criação e a recriação de diferentes representações sobre um mesmo tema, que, dependendo do lugar e do que se pretende estudar, podem ser vistas sob perspectivas diferentes.

Nas palavras de Santos: "[...] para a teoria de Moscovici o sujeito é um ser ativo, construtor da realidade social e nela é construído. Para ele, o sujeito não é simples processador de informações externas ou produto de uma realidade exterior a ele" (2005, p. 17). E, nesse sentido, pode-se dizer que as representações sociais se constroem dentro das relações que são construídas no dia a dia, elas estão nos costumes que são passados de uma geração a outra, no modo de se relacionar com algum objeto, nos ideais de aceitação e negação de uma cultura. As representações estão tanto em grupos de indivíduos como também na constituição do pessoal.

Outra característica da representação social, destacada por Reigota (1998), é o fato de ela não estar ligada somente ao conhecimento científico, ela se constitui, também, de elementos do "senso comum", de um "saber natural", ou seja, dos saberes das massas. "Nas representações sociais podemos encontrar os conceitos científicos da forma que foram aprendidos e internalizados pelas pessoas" (REIGOTA, 1998, p. 12).

Segundo Moscovici (1978), uma representação social é o senso comum que se tem sobre um determinado tema, em que se incluem também preconceitos, ideologias e características específicas das atividades cotidianas (sociais e profissionais) das pessoas, cuja fonte de crescimento é a comunicação de massa.

Dessa forma, na perspectiva de Moscovici, pode-se dizer que as representações sociais são:

Um sistema de valores, ideias e práticas, com uma dupla função: primeiro, estabelecer uma ordem que possibilitará às pessoas orientar-se em seu mundo material e social e controlá-lo; e, em segundo lugar, possibilitar que a comunicação seja possível entre os membros de uma comunidade, fornecendo-lhes um código para nomear e classificar, sem ambiguidade, os vários aspectos de seu mundo e da sua história individual e social (2003, p. 21). 
E é nesta perspectiva que se direciona este estudo. Procuramos identificar as representações sociais sobre a sexualidade na adolescência dos alunos de uma escola pública de Uberaba, MG, compreendendo que elas são construídas não só a partir de elementos científicos, mas, principalmente, a partir do senso comum, da cultura, de ideologias, de preconceitos, enfim, das relações que se estabelecem no dia a dia.

Para a compreensão dessas representações, segundo Moscovici (2003) e Jodelet (2001), é preciso que se identifiquem dois processos: a objetivação e a ancoragem.

A objetivação é um processo pelo qual o objeto da representação passa do abstrato para o concreto. Nas palavras de Moscovici: "Objetivar é reabsorver um excesso de significações materializando-as (e adotando assim uma distância a seu respeito)" (1978, p. 111). Pode-se dizer que a objetivação é um processo direcionado para fora, ou seja, para os outros, no qual se elaboram conceitos e imagens, para reproduzi-los no mundo externo.

Já a ancoragem diz respeito à forma com que a representação e o seu objeto se inserem no social. É o processo em que procuramos classificar, nomear e integrar no meio familiar, ou seja, tornar familiar algo não familiar.

São esses processos que explicam como um componente social transforma um conhecimento em uma representação, e como essa representação transforma o social. É o que buscamos nesta pesquisa. Interessa-nos saber como os alunos compreendem a sexualidade e como esse conhecimento tem influenciado o modo de ser desse grupo de adolescentes.

\section{A subteoria do núcleo central}

A subteoria do núcleo central foi proposta por Abric em 1976, sendo denominada também de abordagem estrutural das representações sociais. Para Abric: "Toda representação está organizada em torno do núcleo central, que determina, ao mesmo tempo, sua significação e sua organização interna. O núcleo central é um subconjunto da representação" (1994 apud SÁ, 2002, p. 67). De acordo com Abric (2000), os elementos de uma representação não apenas são hierarquizados, mas também organizados em torno de um núcleo central constituído por elementos que lhe dão a representação e o seu significado.

Sarubbi Júnior et al. (2013), com relação à teoria do núcleo central, esclarece que, ao estudar as representações sociais de um determinado grupo, é possível encontrar um núcleo figurativo. "Neste núcleo se concentram, de forma coesa, representações que tendem a operar sobre as demais um consenso catalisador, de forma a torná-las homogêneas" (2013, p. 36). O autor esclarece, ainda, que esse 
poder homogeneizador se dá em decorrência da forte significação dos elementos que a constituem. "A teoria do núcleo central (e do sistema periférico) reproduz, figurativamente, uma forma descritiva (estrutural) de como as representações sociais se organizam para um determinado grupo estudado" (SARUBBI JÚNIOR et al., 2013, p. 36).

Especificamente, o núcleo central é uma estrutura que organiza os elementos da representação e, em razão disso, lhe dá sentido. O que distingue o núcleo central do sistema periférico é que o primeiro apresenta maior homogeneidade, coerência e rigidez das representações, enquanto o segundo é mais flexível, instável e heterogêneo. A Figura 1 sintetiza a distinção entre eles.

Figura 1 - Distinção entre núcleo central e sistema periférico

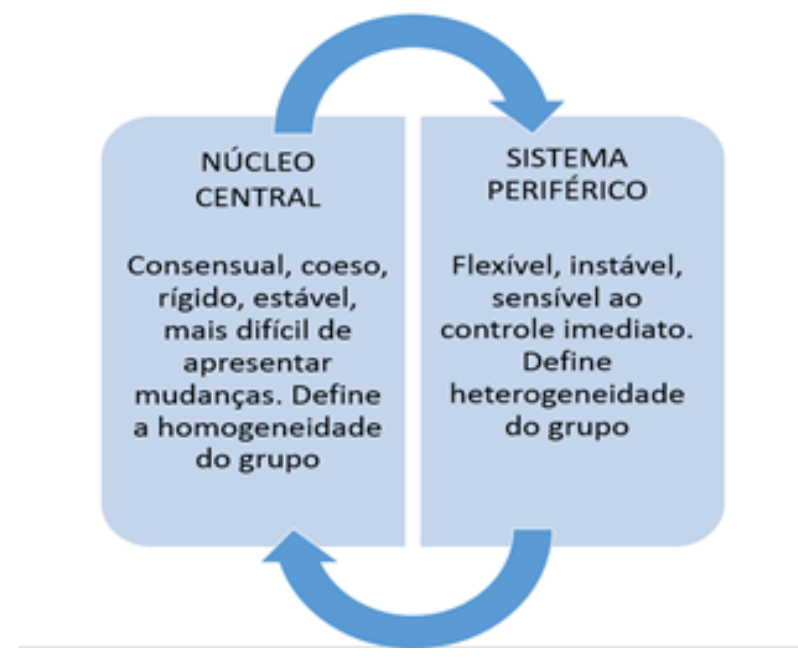

Fonte: Sarubbi Júnior et al. (2013, p. 37).

Sobre a estrutura das representações sociais, é importante ressaltar que, segundo Abric (2000), o núcleo central e o sistema periférico apresentam-se como complementares. O sistema central está ligado à memória coletiva e à história do grupo, o que permite dizer que é determinado pelas condições históricas, sociológicas e ideológicas. A sua função é consensual, permitindo a homogeneidade de um grupo. É o sistema periférico que capta as novas informações ou eventos suscetíveis frente ao núcleo central. O sistema periférico é o responsável por promover a interface entre a realidade concreta e o sistema central. Por ser flexível, modifica-se mais facilmente do que o núcleo central e, em razão disso, assume a função de protetor do núcleo, constituindo a parte operatória da representação. 
Na visão de Abric (2000), a explicitação do núcleo central constitui uma tarefa importante da pesquisa em representações sociais. Uma vez identificados os seus elementos, torna-se possível compreender, refletir e tomar decisões no sentido de alterar a representação, se for necessário.

\section{Técnica de associação livre de palavras}

Segundo Merten (1992), com relação à origem de "associação", foi o filósofo grego Aristóteles (384-322 a.C.), dentro da tradição filosófica da época, o primeiro a tratar desse termo. Em seguida, foi utilizado por Descartes, Hobbes, Leibniz e Locke. Somente por volta de 1880 é que a psicologia, após conquistar status de ciência, elaborou a primeira lista com palavras de associações. Essa lista foi criada por Francis Galton em 1879, dando início a uma nova possibilidade para os estudos em psicologia como método. Posteriormente, esses estudos foram levados também para o campo da psiquiatria, por Wundt, e amplamente usados para o estudo da esquizofrenia, por Bleuler, em 1911.

Ainda segundo Merten (1992, p. 531), em 1895, Freud, juntamente com Breuer, introduziu a "associação livre" como método terapêutico para análises de sonhos e interpretações de lapsos. Jung utilizou a experiência da associação como um meio de diagnóstico para revelar os "complexos". ${ }^{3}$

Jung teve seu primeiro contato com o método associativo no hospital psiquiátrico de Burgholzle, quando ocupou o cargo de segundo assistente, trabalhando juntamente com Bleuler, que recorria ao associacionismo, corrente da psicologia, muito forte na época, para o estudo das combinações e recombinações mentais. Logo, Jung destacou-se na procura dos distúrbios mentais precoces, a que posteriormente foi dado por eles o nome de esquizofrenia.

O método praticado por Jung consistia na organização de uma lista com palavras que não possuíam nenhuma relação entre si, e o indivíduo deveria reagir a cada palavra indutora com uma outra palavra. Era medido o tempo decorrido entre uma resposta e outra. $\mathrm{O}$ que chamou a atenção de Jung, nesse método, foram as reações dos indivíduos diante de algumas palavras indutoras que causavam perturbações. Ele descobriu que essas palavras indutoras e suas reações indicaram que elas haviam atingido um conteúdo emocional no inconsciente, ideia que foi se estruturando através dos casos clínicos atendidos.

Como visto, a associação livre de palavras já era objeto de interesse desde os primórdios das análises de estudo da mente humana, e foi também com esse interesse que Jung, com a psicologia analítica desenvolvida por ele, passou a propor a 
associação livre de palavras como meio de diagnóstico para um dos seus interesses de estudo: os complexos (MERTEN, 1992).

A técnica consiste em apontar um termo indutor para o qual o sujeito deverá responder escrevendo a primeira palavra que lhe vier à mente. Para este estudo, utilizamos a técnica como foi descrita por Merten: "[...] descrição das ideias e imagens que surgem ao sujeito e que o sujeito associa a uma palavra ou tema" (1992, p. 533).

Segundo Merten (1992), atualmente existem muitas variações da técnica de associação de palavras. Além de contribuir com os testes psicológicos projetivos, elas podem ser realizadas por meio de palavras livres, pedindo-se os seus sinônimos ou antônimos; por meio de ligação com uma palavra anterior; ou pedindo aos sujeitos que deem a resposta que a maioria daria ou que ninguém daria.

De acordo com Merten:

O método de associação de palavras está estritamente ligado ao desenvolvimento histórico tanto da Psicologia como da Psiquiatria. As múltiplas investigações empíricas que utilizaram esse método [...] construíram essencialmente, por um lado, para elaborar um grande número de teorias psicológicas, e, por outro lado, para chegar à aceitação do conjunto de conhecimentos que temos hoje em dia (1992, p. 538).

A técnica da associação livre de palavras pode ser utilizada dentro dos mais variados temas em que se deseja trabalhar, tanto na área humana como na saúde, podendo trazer características singulares ou complexas de uma comunidade. Para esta pesquisa, optamos por verificar as representações sociais construídas pelos adolescentes sobre a sexualidade.

\section{0 software EVOC}

Conforme Sarubbi Júnior et al., o software EVOC:

É um conjunto de programas ordenados para o processamento e análise matemática de evocações. [...] um instrumento técnico, informatizado e teórico-metodológico que tem por finalidade gerar dados que auxiliarão o pesquisador a analisar e inferir a forma como se organiza a disposição das representações sociais investigadas (2013, p. 34).

Esse software foi criado por Piérre Vergès em 1999. Ele possibilita que os sistemas centrais e periféricos das representações sociais tornem-se objetos de pesquisa por meio do método de associação de palavras, criando quadrantes que combinam a frequência de palavras evocadas com a ordem e a média (OME) em que elas aparecem. "Para tanto, Vergès arquiteta um instrumento informatizado que permite criar um banco de dados a partir das evocações geradas pelos sujeitos investigados 
pelo método de indução de associação de palavras: o software EVOC" (SARUBBI JÚNIOR et al., 2013, p. 37).

Com relação à escolha desse software, concordamos com Sarubbi Júnior et al.: "[...] as metodologias quantitativas e qualitativas são indissociáveis. Ambas, em movimento, complementam-se, quando direcionadas ao estudo de um mesmo fenômeno, revelando caráter relacional do processo de produção do conhecimento" (2013, p. 10). Os autores destacam, ainda, que o aperfeiçoamento nos instrumentos de pesquisa, além de ser uma exigência real, tem buscado também formas mais ágeis para se obter um resultado esperado, e o uso da tecnologia e, principalmente, de programas que auxiliem pesquisadores em seus campos de trabalho enriquece e abre novas maneiras de fazer pesquisa, ao passo que também exige aperfeiçoamento contínuo dentro das novas possibilidades que a tecnologia traz ao meio científico, como novas formações e qualificação profissional para a utilização dessa ferramenta.

Durante muitos anos, as pesquisas, de forma geral, caracterizavam-se entre dois polos opostos - as quantitativas e as qualitativas. Para Sarubbi Júnior et al. (2013), as pesquisas quantitativas baseavam-se em modelos que envolviam medidas, números, gerações de tabelas e banco de dados, enquanto as qualitativas relacionavam-se diretamente a dimensão subjetiva, variabilidade de pensamento, sentimento e emoção. Isso contribuía para que os campos de pesquisas formassem defensores de métodos mais verdadeiros e válidos de pesquisa.

Entre os altos e baixos de cada tipo de pesquisa em sua história, e depois de um período de rejeição quanto a validade e generalização dos recursos obtidos em pesquisas qualitativas, na década de 1980, surgiu um novo momento para a pesquisa científica, exigindo do investigador a certeza e o rigor dos resultados evidência que passaria a ser a base de toda pesquisa. Surgiu, assim, a necessidade de abertura para as novas formas de conhecimento, fazendo do computador uma ferramenta aliada à pesquisa qualitativa, que viria a abranger, também, posteriormente, áreas como a saúde.

Hoje, a pesquisa quantitativa, aliada à qualitativa, é reconhecida como auxiliar e importante para a construção e a análise de dados coletados. Dessa maneira, o EVOC é considerado como um importante instrumento para identificar e compreender o núcleo central e o sistema periférico das representações sociais. Dentre os seus programas, utilizamos as seguintes etapas: a) Lexique - preparação e depuração do corpus de análise; b) Trievoc - correção das palavras e limpeza das palavras inúteis; c) Listvoc - lista de todas as palavras; d) Rangmot - frequência e distribuição das classificações para cada palavra, o que permite elaborar o Rangfrq; e) Tabrgfr - identificação das palavras que compõem o núcleo central e os elementos periféricos das representações sociais. 


\section{As contribuições da técnica de associação livre de palavras e o software EVOC: diálogo com os dados}

Como mencionado anteriormente, os dados para este estudo foram coletados por meio da técnica de associação livre de palavras e analisados com o auxílio do software EVOC.

Inicialmente, pedimos aos participantes para escreverem três palavras que lhes viessem à mente após ler o termo indutor: sexualidade na adolescência. Em seguida, pedimos que assinalassem a palavra mais importante, justificando sua escolha.

Dessa técnica, obtivemos um total de 413 palavras, que foram organizadas em um arquivo e processadas no software EVOC. Esse programa permitiu identificar e organizar as palavras de acordo com a hierarquia dada pela combinação da frequência (F) com a ordem média das evocações (OME).

Segundo Sarubbi Júnior et al., o processamento dos dados no EVOC “[...] auxilia a visualização da disposição das representações sociais, possibilitando ao pesquisador maior objetividade na análise inferencial das representações investigadas" (2013, p. 37).

Assim, com essa técnica de análise, foi possível identificar um quadro de quatro casas (Figura 2). Nesse quadro, as palavras evocadas foram distribuídas e organizadas em elementos centrais e periféricos.

Figura 2 - Quadrantes do EVOC

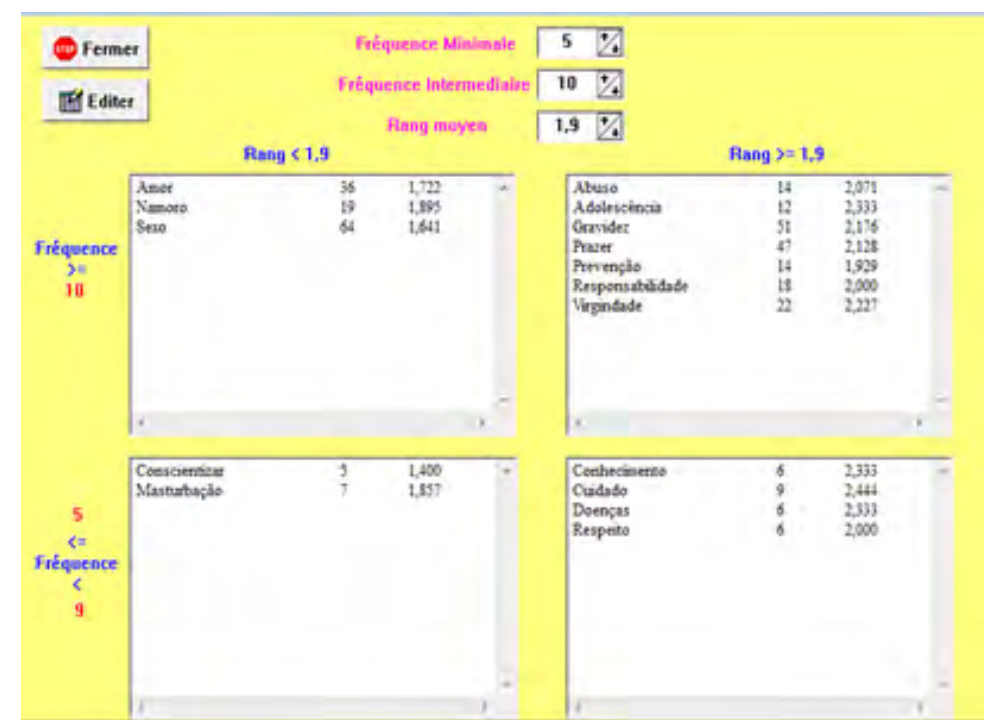

Fonte: dados da pesquisa. 
O Rang, ou seja, a média das ordens médias de evocação, foi de 1,9, enquanto a frequência média ficou em 10 e a mínima, em 5 .

Passamos à análise dos quadrantes.

\section{Primeiro quadrante}

No primeiro quadrante superior à esquerda, encontram-se as palavras mais frequentes e prontamente evocadas, que provavelmente constituem o núcleo central das representações. São elas: amor, namoro e sexo.

De acordo com Sarubbi Júnior et al., essas evocações "[...] foram mencionadas por um maior número de sujeitos e, quando evocadas, aparecem nas primeiras posições" (2013, p. 75). As palavras desse quadrante ocupam, na estrutura da representação, "[...] uma perspectiva coesa, estável e menos sensível ao contexto imediato, devido à alta consensualidade que possuem neste universo investigativo" (2013, p. 75). Nesse sentido, pode-se dizer que o núcleo central apresenta esta importante função: organizar e dar sentido à representação social.

A palavra sexo foi a mais evocada (64 vezes), o que parece indicar que, para esses adolescentes, a sexualidade é sinônimo apenas de sexo. É o que podemos verificar nas suas justificativas:

Sexo faz parte da vida. Sem ele eu não estaria aqui (7002) ${ }^{4}$

O que eu considero mais importante é o sexo porque ele e o princípio da vida humana (8073).

Um ato normal praticado por todos (9118).

O sexo é um ato que acontece quando dois corpos se atraem (8085).

Sexo é necessidade (9138).

O que se percebe nas afirmações dos adolescentes é a compreensão limitada do termo sexualidade. Para eles, a sexualidade apresenta uma visão unicamente biológica. A não informação adequada do termo e mesmo a ausência de uma orientação sexual, no desenvolvimento desses adolescentes, podem estar influenciando as representações sociais em construção.

Aquino e Martelli (2012, p. 9) corroboram esse pensamento ao apresentarem os resultados de suas pesquisas, que mostram a tendência de os professores permanecerem com uma concepção biológica da sexualidade, enfatizando apenas atividades de caráter "higienista e preventivo no âmbito da saúde". As autoras mostram, ainda, a relação de sinônimo inadequada que se discute nas salas de aula de ciências, apenas com o propósito de informar questões sobre "doenças sexualmente transmissíveis, sistema reprodutor, contracepção, dentre outros” (2012, p. 9).

Meyer, Klein e Andrade (2009) também afirmam que muitas atividades desenvolvidas na escola com relação à sexualidade assumem um enfoque tradicional, 
a partir de um referencial médico que privilegia somente a promoção da saúde sexual, ou seja, utilizam uma abordagem de caráter pontual, priorizando apenas as informações, sem, contudo, problematizar questões ligadas a cultura, amor e prazer, que dizem respeito à sexualidade.

A segunda palavra mais evocada desse quadrante foi amor. Citada por 36 adolescentes, também integra o rol de palavras que possivelmente constituem o núcleo central das representações. Para esse grupo de adolescentes, a sexualidade traduz-se no termo amor. Esse termo ancora-se nos seguintes sentimentos:

Amor é tudo na vida (7024).

Gerar filhos é mais importante (7037).

Porque tem que ter o amor para acontecer isso tudo (8084).

Pois em uma relação sexual é estabelecido principalmente o amor (8091).

Amor é o prazer da felicidade (9125).

Com o amor e mais fácil de lidar com assunto e mais liberdade, e compromisso (9133).

A terceira palavra, namoro, foi evocada por 19 adolescentes. Para eles, a sexualidade é compreendida a partir do que entendem por namoro ou a relação que se tem com um namorado. Mostram, também, nessas representações, os desejos e os conflitos familiares na conquista por um namorado. Todos esses sentimentos incorporam a ideia de sexualidade que esses adolescentes estão construindo.

O namoro é a primeira coisa que se deve acontecer pois daí começa a planejar seu futuro (8061).

Namorar para ver se já pode fazer sexo (7022).

Namoro é ficar com seu parceiro (8089).

Sexualidade é namoro, é companheirismo (9114).

As vezes a família não te libera para namorar, ai você tenta faze as opções erradas e acaba namorando (8097).

Assim, os termos amor, namoro e sexo traduzem o que os participantes desta pesquisa compreendem por sexualidade. Para a maioria, a sexualidade está ligada, principalmente, ao ato sexual ou a fazer sexo. Para alguns, esse ato vem acompanhado do sentimento de amor e pode ser o resultado de uma relação com um parceiro.

\section{Segundo, terceiro e quarto quadrantes}

Esses três quadrantes representam a zona de periferia, ou seja, os elementos periféricos, contendo os “[...] termos evocados nas últimas posições e/ou com baixa frequência média. São evocações flexíveis e instáveis, pois estão mais sensíveis ao contexto imediato de um menor número de sujeitos, ou, ainda, com pouca representatividade" (SARUBBI JÚNIOR et al., 2013, p. 76). 
O segundo quadrante superior à direita, ou segunda periferia, contém as palavras que possuem frequência mais alta, porém as evocações aparecem nas últimas posições, ou seja, a OME (ordem média das evocações) é alta. Neste estudo, compõem esse quadrante as palavras: abuso, adolescência, gravidez, prazer, prevenção, responsabilidade e virgindade.

Com 51 evocações, a palavra gravidez aparece com o sentido de que a sexualidade implica uma relação sexual, e esta pode resultar numa gravidez indesejada, como o exemplo que se segue: "Muitas meninas na adolescência tem a curiosidade de exercer uma atividade sexual só que para isso elas precisam estar cientes que estão correndo o risco de engravidar ou pegar uma doença sexualmente transmissível" (8096).

A palavra prazer, evocada 47 vezes, também traz a compreensão do termo sexualidade associado ao ato sexual, como pode ser visto nos exemplos: "Essencial para a alegria no ato sexual" (9101); "Se não tiver não ocorre o sexo" (9102).

Virgindade foi evocada 22 vezes, associada a sentimentos de "perda" e com situações de medo. "Medo de perdê-la" (8092); "Porque estamos perdendo uma coisa importante para as nossas vidas" (7013); "É uma coisa séria porque é a primeira vez que vai ter um ato sexual” (8053); “[...] ficamos com dúvidas de como vai ser, o que é a sensação e etc." (8053).

Em seguida, com 18 evocações, aparece a palavra responsabilidade. Novamente, o sentido dessa palavra associa-se ao ato sexual, referindo-se à necessidade de ter responsabilidade diante do sexo. Nesse sentido seguem as afirmações: "Para fazer sexo tem que ter muita responsabilidade porque pode engravidar" (8068); "Tem menina de 13 anos por aí e que já está grávida" (8063); "Pois todas as pessoas, na minha opinião, tem que ter responsabilidade sobre os riscos de DST, gravidez, etc." (7008).

As palavras abuso e prevenção foram evocadas 14 vezes. A primeira apresenta alguns sentimentos preocupantes, pois parece que esses adolescentes relacionam a sexualidade com ações que denotam abuso e/ou estupro. Essas representações podem estar sendo construídas a partir da influência da mídia ou de experiências na própria família, como demonstram os seguintes relatos: "Pois tem muitos homens que estrupam adolescentes" (7050); "Hoje em dia é uma coisa cada vez mais comum e constante em casa e na rua" (9117); "Abuso sexual, estupro, toda hora sai no noticiário na TV" (9112).

Já a palavra prevenção também evidencia a necessidade de se cuidar diante de uma relação sexual. Nesse sentido, destaca-se: "A prevenção é essencial para não ter problemas futuros, como por exemplo uma gravidez na adolescência (8088)"; 
"Metade dos adolescentes de hoje não tem ideia de meios de prevenção e tudo mais" (9127).

E, por último, aparece a palavra adolescência, como sinônimo de sexualidade, com 12 evocações. Os participantes justificam essa palavra da seguinte maneira: "Adolescência é uma fase rebelde da vida" (7008); “[...] são os adolescentes que mais tem que saber sobre sexo, porque já está chegando a hora” (7021).

Vale ressaltar que os elementos desse quadrante, ou seja, as palavras abuso, adolescência, gravidez, prazer, prevenção, responsabilidade e virgindade, podem, dependendo de ações do meio, migrar para o núcleo central, pois elas são as que mais se aproximam desse núcleo.

No terceiro quadrante inferior à esquerda, encontram-se os elementos que figuram como "contraste" do núcleo central, com as palavras masturbação e conscientizar. Esse quadrante é construído de evocações que possuem baixa frequência, porém aparecem nas primeiras posições, isto é, possuem baixa OME, conforme apontam Sarubbi Júnior et al.:

Isto quer dizer que, embora estas palavras tenham sido evocadas por um menor número de sujeitos, quando o foram, apareceram nas primeiras posições. Pode sugerir um ou mais subgrupos, uma minoria que evoca termos que tem uma importante posição, mas que não são citadas pela maioria, exprimindo o contrate de ideias entre pequeno e grande grupo (2013, p. 76).

A palavra masturbação, que foi evocada 7 vezes, está associada à sexualidade com as seguintes justificativas: "Masturbação: sexo solitário" (7012); "Transar sozinho" (7020); "Prazer com mais frequência" (7037).

Já a palavra conscientizar foi citada por 5 adolescentes, que a justificaram como sendo a mais importante: "Conscientizar para a gente ficar sabendo das coisas que vamos fazer" (7010); "Acho importante todas as pessoas ficarem cientes dos riscos" (7042).

$\mathrm{O}$ quarto e último quadrante, inferior à direita, contém os elementos que possuem frequência baixa e alta OME. As palavras foram evocadas por um pequeno número de sujeitos e nas últimas posições: conhecimento, cuidado, doenças e respeito.

A palavra cuidado, que foi evocada por 9 adolescentes, está associada à compreensão do termo sexualidade pelas seguintes justificativas: "Temos que ter muito cuidado e não fazermos coisas erradas" (8083); “O cuidado é essencial não só na adolescência, mas também na fase adulta. Pois pode lhe ser transmitida doenças sexualmente transmissíveis" (8067).

As palavras conhecimento, doenças e respeito foram evocadas 6 vezes. O conhecimento relaciona-se ao desejo de conhecer tudo sobre o sexo, como mostram as 
justificativas: "É importante ficar sabendo sobre sexo e de muitas coisas - é tudo conhecimento" (9135); "Conhecimento do que é certo" (7030).

A palavra doenças relaciona-se à sexualidade no sentido de evitar doenças sexualmente transmissíveis: "Desde pequeno todas as pessoas falam sobre a AIDS - E quando for fazer o ato sexual ser cauteloso e usar preservativo" (8093).

A palavra respeito aparece sinalizando a necessidade de respeito com o outro; para isso, apontam a importância de: "Conhecimento do que é certo" (7030); "Porque uma relação sexual com carinho e respeito é bem mais saudável” (9132).

Machado e Aniceto (2010) destacam a importância do sistema periférico como complemento indispensável do núcleo central, “[...] uma vez que protege esse núcleo, atualiza e contextualiza constantemente suas determinações normativas, permitindo uma diferenciação em função das experiências cotidianas nas quais os indivíduos estão imersos" (2010, p. 357).

Em relação a este estudo, os elementos do sistema periférico, ou seja, as palavras: abuso, adolescência, gravidez, prazer, prevenção, responsabilidade, virgindade, masturbação, conscientizar, conhecimento, cuidado, doenças e respeito, fazem a interface entre a realidade concreta e o sistema central.

\section{Considerações finais}

O objetivo desta pesquisa foi identificar o núcleo central e o sistema periférico das representações sociais construídas por alunos da educação básica de uma escola municipal de Uberaba, MG, sobre a sexualidade na adolescência. Nosso esforço com este trabalho foi o de tornar familiares os fenômenos desconhecidos com relação à construção das representações. Procuramos mostrar em que e como elas se ancoram, no sentido de compreender as possíveis orientações advindas da familiaridade dessas representações, até então desconhecidas. Partimos do princípio de que a identificação de uma representação pode ir além da compreensão de como ela tem interferido no modo de pensar e agir das pessoas, muito mais do isso, ela pode também, e principalmente, "orientar comportamentos".

As análises da técnica de associação livre de palavras processadas no programa EVOC, ou seja, a identificação do núcleo central e do sistema periférico das representações sociais sobre a sexualidade na adolescência, mostram que os participantes deste estudo constroem essas representações a partir de sentimentos e percepções que se ancoram em elementos que denotam pouca orientação ou falta de informações necessárias. As representações tornam familiares questões que são preocupantes. Para a maioria, a compreensão sobre sexualidade associa-se unicamente ao ato sexual, considerando-a apenas como sinônimo de coito. Esses 
indivíduos desconhecem que a sexualidade “[...] é a energia que motiva a encontrar o amor, o contato e a intimidade e se expressa na forma de sentir, na forma de as pessoas tocarem e serem tocadas”, conforme a Organização Mundial da Saúde (1975 apud EGYPTO, 2012, p. 15-16).

Esses dados tornam-se mais preocupantes ainda, diante do que afirma a Organização Mundial da Saúde: "A sexualidade influencia pensamentos, sentimentos, ações e interações e tanto a saúde física como a mental. Se saúde é um direito humano fundamental, a saúde sexual também deveria ser considerada um direito humano básico" (1975 apud EGYPTO, 2012, p. 15-16).

Destacamos, assim, a necessidade de um trabalho de orientação sexual nas escolas, pois, para os participantes deste estudo, a sexualidade apresenta uma visão unicamente biológica. A não informação adequada do termo, ou mesmo a ausência de uma orientação sexual, no desenvolvimento desses adolescentes, pode estar influenciando as representações sociais em construção. Essas representações, como afirma Moscovici (2003), influenciam pensamentos, ações e modos de ser das pessoas. E, na escola, interessam-nos, principalmente, a disposição e o desejo para aprender.

\section{Notas}

1 Este estudo foi aprovado pelo Comitê de Ética em Pesquisa envolvendo seres humanos da Universidade de Uberaba, MG, CAAE: 30687314.0.0000.5145 e parecer nº 640.795.

2 Metrossexual é uma junção das palavras "metropolitano" (cidade, metrópole) e "sexual”, cujo significado se refere a um homem urbano que se preocupa em cuidar da aparência.

3 São grupos de ideias ou imagens carregadas emocionalmente, que possuem em seu núcleo um arquétipo correspondente (NASSER, 2010).

4 As falas dos adolescentes, nas respostas do questionário, foram transcritas, neste texto, em itálico e na forma de citação direta. Para garantir o anonimato, os participantes foram nomeados por um número: 7 , quando for da turma do $7^{\circ}$ ano; 8, quando for do $8^{\circ}$ ano; e 9 , quando for do $9^{\circ}$ ano. Em seguida, aparece um número de 1 a 143.

\section{Referências}

ABERASTURY, A. et al. Adolescência. Porto Alegre: Artes Médicas, 1983.

ABRIC, J. C. A abordagem estrutural das representações sociais. In: MOREIRA, A. S. P.; OLIVEIRA, D. C. (Org.). Estudos interdisciplinares de representação social. 2. ed. Goiânia: AB Editora, 2000. p. 27-38.

AQUINO, C.; MARTELLI, A. C. Escola e educação sexual: uma relação necessária. In: SEMINÁRIO DE PESQUISA EM EDUCAÇÃO DA REGIÃO SUL - ANPED SUL, 9, 2012. Anais... Caxias do Sul: PPGEDU/UCS, 2012. p. 1-16. 
ARRUDA, A. Sexualidade e informação: recado dos jovens paraibanos. In: PAIVA, V. (Org.). Em tempos de AIDS. São Paulo: Sumus, 1992. p. 139-144.

BOCK, A. M. B. A adolescência como construção social: estudo sobre livros destinados a pais e educadores - adolescência como uma construção social. Revista Semestral da Associação Brasileira de Psicologia Escolar e Educacional, Campinas, v. 11, n. 1, p. 63-76, jan./jun. 2007.

BRASIL. Ministério da Educação. PCN - Parâmetros Curriculares Nacionais: pluralidade cultural: orientação sexual. 3. ed. Brasília, DF: Secretaria de Educação Fundamental, 2001. v. 10.

DAVIM, R. M. B. et al. Adolescente/adolescência: revisão teórica sobre uma fase crítica da vida. Revista da Rede de Enfermagem do Nordeste, Fortaleza, v. 10, n. 2, p. 131-140, abr./jun. 2009.

EGYPTO, A. C. Orientação sexual na escola: um projeto apaixonante. 2. ed. São Paulo: Cortez, 2012.

EISENSTEIN, E. Adolescência: definições, conceitos e critérios. Revista Adolescência \& Saúde, Rio de Janeiro, v. 2, n. 2, p. 6-7, jun. 2005. Disponível em: <http://www.adolescenciaesaude.com/ detalhe_artigo.asp?id=167>. Acesso em: 14 nov. 2018.

ERIKSON, E. H. Infância e sociedade. Rio de Janeiro: Zahar, 1987.

FERREIRA, B. W. O cotidiano do adolescente. Petrópolis: Vozes, 1995.

GALLATIN, J. E. Adolescência e individualidade: uma abordagem conceitual da psicologia da adolescência. Trad. Antônio Carlos Amador Pereira e Rosane Amador Pereira. São Paulo: Harper \& Row do Brasil, 1978.

HARRIS, R. H. Vamos falar de sexo: crescimento, corpos em mudança, sexo e saúde sexual. Lisboa: Terramar, 1994.

HURLOCK, E. B. Desenvolvimento do adolescente. São Paulo: McGraw-Hill do Brasil, 1979.

JODELET, D. Representação sociais: um domínio em expansão. In: (Org.). Representações sociais. Rio de Janeiro: EdUerj, 2001. p. 17-44.

MACHADO, L. B.; ANICETO, R. A. Núcleo central e periferia das representações sociais de ciclos de aprendizagem entre professores. Revista Ensaio: Avaliação e Políticas Públicas em Educação, Rio de Janeiro, v. 18, n. 67, p. 345-364, abr./jun. 2010.

MERTEN, T. O teste de associação de palavras na psicologia e psiquiatria: história, método e resultados. Análise Psicológica. 1992. Disponível em: <http://repositorio.ispa.pt/bitstream/10400.12/1883/1/1992_4_531.pdf>. Acesso em: 06 jun. 2016.

MEYER, E. E.; KLEIN, C.; ANDRADE, S. S. Sexualidade, prazeres e vulnerabilidade: questões para a educação escolar. Curitiba: Secretaria de Estado da Educação; Superintendência de Educação; Departamento de Diversidades; Núcleo de Gênero e Diversidade Sexual, 2009. p. 81-89.

MOSCOVICI, S. A representação social da psicanálise. Trad. Álvaro Cabral. Rio de Janeiro: Zahar, 1978.

Representações sociais: investigações em psicologia social. Petrópolis: Vozes, 2003. 
NASSER, Y. B. d'A. N. A identidade corpo-psique na psicologia analítica. Revista Estudos e Pesquisas em Psicologia, Rio de Janeiro, v. 10, n. 2, p. 325-338, ago. 2010. Disponível em: <http:// pepsic.bvsalud.org/scielo.php?script=sci_arttext\&pid=S1808-42812010000200003\&lng=pt\&nr $\mathrm{m}=$ iso $>$. Acesso em: 05 out. 2018.

REIGOTA, M. Meio ambiente e representação social. 3. ed. São Paulo: Cortez, 1998.

SÁ, C. P. Núcleo central das representações sociais. Petrópolis: Vozes, 2002.

SANTOS, M. F. S. A teoria das representações sociais. In: PITTA, D. P. R. (Org.). Ritmos do imaginário. Recife: Editora Universitária da UFPE, 2005. p. 15-28.

SARUBBI JÚNIOR, V. et al. Tecnologias computacionais para o auxílio em pesquisa qualitativa - software EVOC. São Paulo: Schoba, 2013.

SENNA, S. R. C. M.; DESSEN, M. A. Contribuições das teorias do desenvolvimento humano para a concepção contemporânea da adolescência. Psicologia: Teoria e Pesquisa, Brasília, DF, v. 28, p. 101-108, 2012.

SHIMIZU, A. M.; MENIN, M. S. S. Representações sociais de lei, justiça e injustiça: uma pesquisa com jovens argentinos e brasileiros utilizando a técnica de evocação livre de palavras. Estudos de Psicologia, Natal, v. 9, n. 2, p. 239-247, 2004. Disponível em: <http://www.scielo.br/pdf/epsic/ v9n2/a05v9n2.pdf>. Acesso em: 14 nov. 2018. 